Черных Сергей Иванович

д-р филос. наук, доцент, заведующий кафедрой ФГБОУ ВО «Новосибирский государственный аграрный университет» г. Новосибирск, Новосибирская область

\title{
ЭКОСИСТЕМА ОБРАЗОВАНИЯ
}

\section{В УСЛОВИЯХ ЦИФРОВЫХ ТЕХНОЛОГИЙ}

Аннотация: в статье рассматриваются дискуссионные аспектьл формирования современных образовательных взаимодействий в условиях дигитализации образования. Используя концеепџию «творческого разрушения» P.Аднера и Р.Капура, автор рассматривает соотношение экосистемь российского образования и собственно образования как «полигона», на котором осуществляются образовательные трансформации. Автор приходит к выводу, что противоречие в темпах и векторах трансформации образовательной экосистемы и собственно образования приводят к выраженному замедлению проводимых реформ.

Ключевые слова: экосистема образования, дигитализация, образовательные технологии, цүифровая готовность, аутентичная эфффективность.

Дискуссионная полемика вокруг вопросов, связанных с начинающими формироваться в XXI веке новыми парадигмами образования, не прекращается. Это определяется явно выраженными трендами разновекторности в развитии экосистем традиционного (классического или «прусского»), модернизационного (цифрового, образования «общества знания», открытого, непрерывного, онлайнобразования (виртуального, дистанционного, МООС-образования) и инклюзивного образования. И старые и новые образовательные парадигмы, прокламируя единую по форме цель (обучение в сочетании (или без сочетания) с воспитанием) достаточно явственно различаются по принципам и методам достижения этой цели. Развитие конвергентных образовательных технологий находится в самом 
начале пути, а частные образовательные методики, несмотря на их «прогрессивность», в силу различных причин не могут приобрести статус «всеобщих».

Подобная ситуация давно сложилась в бизнесе и это заставило профессора стратегии и предпринимательства Дартмутского колледжа Рона Аднера, и Рахула Капура, профессора Уортонской школы бизнеса, задуматься над вопросом о том «... почему одни новые технологии быстро вытесняют своих предшественников, а другие завоевывают позиции постепенно?». По их мнению, для этого надо усвоить две вещи. «Во-первых, что технологию нельзя рассматривать в отрыве от экосистемы, которая ее поддерживает, и во-вторых, что в конкуренцию вступают не столько технологии, сколько старая и новая экосистемы» [1]. Они, рассмотрев подобные принципы (в применении к бизнес-технологиям и бизнес-экосистемам) пришли к заключению о том, что «сила и зрелость элементов, составляющих экосистему», определяют одновременно два запараллеленных процесса: успешность новых технологий и востребованность старых [1]. И это был очень важный в методологическом отношении вывод, так как его экспликация (как методологического принципа) на развитие других типов социальных взаимодействий помогло бы выявить достаточность или недостаточность оснований для их успешной трансформации (модернизации).

Структурно Р. Аднер и Р. Капур представляют экосистему как «ряд дополнительных элементов - технологий (уже статусированных социально), услуг стандартов, нормативных требований» [1]. Однако, если эксплицировать понятие «экосистемы» на «экосистему образования», то неизбежно придется включить в нее сообщество задействованных в этой экосистеме индивидов. С нашей точки зрения это необходимо в силу специфики самого образования, как системной совокупности обучения и воспитания, что отличает его от производства/бизнеса, как социального института, обладающего массой особенностей социального института, становящегося самой объемной услугой в мире.

Статусированные технологии, предоставляемые услуги, фиксированные стандарты и нормативные требования у трех имеющихся на сегодня образовательных парадигм достаточно различны, и мы вполне можем говорить о том, что 
две формирующиеся парадигмы (E-leaning образование и инклюзивное образование) в известной мере можно представить как «новые технологии образовательных взаимодействий», отличающиеся от традиционного, основанного на «прусской модели образовательного взаимодействия» [2].

Доктор педагогических наук Джеки Герштейн считает, что основные отличия «прусской модели» от постклассических вариантов образовательных взаимодействий, связаны с четырьмя моментами: ролевыми статусами учителя и ученика, качеством учебных программ, системой оценок и педагогическими технологиями. Исходя из этих позиций она составила таблицу различий в образовании XXI века и традиционном образовании.

Таблица 1

Таблица доктора Д. Герштейн [3]

\begin{tabular}{|l|l|}
\hline \multicolumn{1}{|c|}{ Образование в ХХІ веке } & \multicolumn{1}{|c|}{ Tрадиционное образование } \\
\hline Ученик в центре процесса обучения & $\begin{array}{l}\text { В центре процесса обучения содержание зна- } \\
\text { ния }\end{array}$ \\
\hline $\begin{array}{l}\text { Преподаватель - это тот, кто направляет } \\
\text { ученика (тренер, наставник) }\end{array}$ & Эксперт и источник знания - учитель \\
\hline $\begin{array}{l}\text { Использование интернета как информацион- } \\
\text { ной базы }\end{array}$ & $\begin{array}{l}\text { Унифицированный по структуре предмета } \\
\text { единственный учебник }\end{array}$ \\
\hline $\begin{array}{l}\text { Ошибки и заблуждения - нормальная часть } \\
\text { учебного цикла }\end{array}$ & $\begin{array}{l}\text { Совершенство во всем - требование как к учи- } \\
\text { телю, так и к ученику }\end{array}$ \\
\hline $\begin{array}{l}\text { Формативное (ежедневное оценивание) уче-- } \\
\text { ников }\end{array}$ & $\begin{array}{l}\text { Итоговая оценка (урок, экзамен) для отчетно- } \\
\text { сти }\end{array}$ \\
\hline $\begin{array}{l}\text { Мультисенсорная среда обучения для созда- } \\
\text { ния практической экосистемы }\end{array}$ & $\begin{array}{l}\text { Сосредоточенность обучения на интеллекту- } \\
\text { альной сфере отношения между членами обра- } \\
\text { зовательной общности не рассматриваются }\end{array}$ \\
\hline $\begin{array}{l}\text { Учащиеся самостоятельно создают содержа- } \\
\text { ние образовательных взаимодействий }\end{array}$ & $\begin{array}{l}\text { Учащиеся изучают содержание, которое со- } \\
\text { здают другие }\end{array}$ \\
\hline $\begin{array}{l}\text { Учащиеся больше работают и выступают в } \\
\text { учебное время, чем учитель }\end{array}$ & $\begin{array}{l}\text { Большую часть работы и говорения выполняет } \\
\text { учитель }\end{array}$ \\
\hline $\begin{array}{l}\text { Весь процесс обучения основан на цифро- } \\
\text { вых технологиях }\end{array}$ & $\begin{array}{l}\text { Образовательные технологии реализуются как } \\
\text { дополнение, специализация, довесок к субъект- } \\
\text { объектному отношению учитель-ученик }\end{array}$ \\
\hline $\begin{array}{l}\text { Некорректное поведение - перспектива для } \\
\text { роста и корректируется в группе учащихся }\end{array}$ & $\begin{array}{l}\text { Некорректное поведение осуждается и наказы- } \\
\text { вается обучающим субъектом }\end{array}$ \\
\hline $\begin{array}{l}\text { Социальный и эмоциональный интеллект - } \\
\text { обязательная часть обучения }\end{array}$ & $\begin{array}{l}\text { Развитию социального и эмоционального ин- } \\
\text { теллекта почти не уделяется внимания }\end{array}$ \\
\hline
\end{tabular}

Сведенные воедино отличия демонстрируют существенную разницу в ключевых моментах традиционного образования и образования XXI века. Однако во 
многом это разница не в обучении как образовательном взаимодействии, а разница в элементах экосистемы образования. Синкретизм традиционной системы (Вильгельм фон Гумбольдт, консерваторы, утилитаристы, новаторы) сменяется сегодня синкретизмом двух экосистем - экосистемы, принадлежащей новым цифровым технологиям и технологиям, которые модернизируют старую образовательную систему. Образование 2.0 и 3.0 все более приходят в конфликт с образованием 4.0. Это происходит по всем структурным элементам экосистемы: технологиям, услугам, стандартам, нормативным требованиям. Это выражено не только «технически», но выражается в поколенческих ценностях и смыслах, закладываемых в структуру образовательного взаимодействия (теперь уже на протяжении всей жизни). Таким образом, образовательные экосистемы, вступая в конкуренцию, решают разные задачи. Старая (традиционное образование) - задачи по модернизации, новая (образовательная XXI века) - задачи по «завоеванию» образовательного пространства.

Примечание. Это проблемы хорошо рассмотрень в истории педагогической мысли, поэтому здесь я не буду на них останавливаться спещиально.

Нарастающая интеграция образовательной экосистемы, которая обусловлена дигитализацией и глобализацией, определяет в качестве исходных ценностей и смыслов критическое мышление и креативность, умение работать в команде, эмоциональный и социальный интеллект, ответственность (личную -!) за принятие решений, готовность к «служению» другим и когнитивную гибкость. Именно эти ценности и смыслы определяют формирование и дальнейшее развитие обучающихся в условиях новой экосистемы образования. В основе этой экосистемы лежат, таким образом, не только цифровые технологии, но стратегия сложных и взаимообусловленных переходов от коллективного обучения к индивидуализации, а от нее, через дифференциацию к персонализации образовательных взаимодействий. Именно эта мировая тенденция изменяет природу глобального образовательного пространства, а равно и национальных образовательных экосистем от форматов 2.0 и 3.0 к формату 4.0, который соответствует VI технологическому укладу в достаточной (но полной ли?) мере. Именно такие 
переходы, по мнению Елены Михайленко и Тода Блейтона, канадских исследователей образования, лежат в основе концепций гражданского образования (Tibbitts, Feruekes\&Totten, 2011), образование социальной справедливости (Adams, 2016), трансформирующегося обучения (Mezirow, 200) [4].

Осложняющим обстоятельством для формирования российского образовательного пространства формата 4.0 является неразрешенное противоречие между эффективностью российского образования (исчисляемого в основном как эффективность интеллектуальности человеческого потенциала) и его материально-техническим обеспечением (индекс развития образования). Если по первой позиции Россия занимает 13 место (из 188 стран), то по второй только 32-е, а итоговый рейтинг составляет только 26-е место из 188 стран.

Подобная ситуация подчеркивает то, что в означенной выше цепи переходов Россия находится на этапе перехода от коллективизации к индивидуализации как по человеческому потенциалу, так и по материально-технической базе на этапе. То есть до «нового синкретизма» российскому образовательному пространству предстоит долгий путь. На этом пути, как правило, в рамках трансформации и «старой» и «новой» экосистем рождается много программных документов разного уровня - от законов (например «Закон об образовании в Российской Федерации» 2012 года) до «стратегий» разного уровня и сроков [5; 6].

В этих документах явственно выражены смыслы и ценности модернизации традиционной экосистемы, что еще более инициирует разные векторы развития российского образовательного пространства. Это говорит о том, что пока политика в области образования не будет нести в себе генерализующего начала (со стороны государства, к примеру) ситуация стратегической неопределенности в образовательной политике будет нарастать, как будет нарастать и глобальное (уже!) отставание российского образования.

\section{Сиисок литературы}

1. Аднер Р. Кошмарный сон новатора / Р. Аднер, Р. Капур [Электронный pecypc]. - Режим доступа: http://hbr-russia.ru/innovatsii/teknologii/a 19171/ 
2. Черных С.И. Анализ трансформации образовательных взаимодействий как основы функционирования и развития субъектов образования (индивидов, коллективов, общества и государства) // Образовательное пространство в условиях информатизации общества / С.И. Черных. - Новосибирск: Изд-во НГАУ, 2011. $-254 \mathrm{c}$.

3. Girstain D. Whats in and what's out in education [Электронный ресурс]. Режим доступа: http://usergeneratededucation.wordpress.com/2014/01/10/whats-inand- what's-out-in-education/

4. Михайленко Е. Учебные модели свободы / Е. Михайленко, Т. Блейон [Электронный ресурс]. - Режим доступа: http:// education-ua.org/ua/articles/928navchalni-modeli-svobodi

5. Кондаков А. Образование 3.0: Большая перемена [Электронный ресурс]. - Режим доступа: wiki.ippk.ru/images/5/5f/3-Кондаков-образование-3.0.pdf

6. Клячко Т.Л. Стратегия для России: образование / Т.Л. Клячко, С.Г. Мурылев. - М.: ИД «Дело» РАНХ и ГС, 2018. - 118 с. 